\title{
Evolution of Microstructure and Internal Stresses in Multi-Phase Oxide Scales Grown on (110) Surfaces of Iron Single Crystals at $650{ }^{\circ} \mathrm{C}$
}

\author{
C. Juricic $\cdot$ H. Pinto $\cdot$ D. Cardinali $\cdot$ M. Klaus • \\ Ch. Genzel · A. R. Pyzalla
}

Received: 14 May 2008/Revised: 30 June 2009/Published online: 29 July 2009

(C) The Author(s) 2009. This article is published with open access at Springerlink.com

\begin{abstract}
The evolution of microstructure and growth stresses in oxide scales grown on a (110) iron single crystal surface at $650{ }^{\circ} \mathrm{C}$ was studied by electron backscatter diffraction and in situ energy-dispersive diffraction with synchrotron radiation. Within this high temperature regime, the oxidation kinetics and scale microstructure were not significantly different from those encountered in the oxidation of ferrous polycrystals. Thus, epitaxial strains did not determine the stress state within the oxide scale. Relevant sources of growth stresses were inferred to be volumetric differences between the iron oxides in the early stages, and later, inner oxide formation, scale consumption as well as pore formation. These sources caused time-dependent stress cycles in magnetite and wüstite during oxidation. In the hematite layer stress cycles did not occur and creep appeared to be the predominant stress relieving mechanism. On cooling, the differences in thermal expansion caused residual stress gradients through the oxide scale.
\end{abstract}

Keywords Iron single crystal · Oxidation · Energy-dispersive diffraction · In situ stress analysis · Residual stress gradients

C. Juricic $\cdot$ H. Pinto $(\bowtie) \cdot$ D. Cardinali

Max-Planck-Institut für Eisenforschung GmbH, Max-Planck-Strasse 1, 40237 Düsseldorf, Germany e-mail: h.pinto@mpie.de

\section{Klaus}

Institut für Werkstoffwissenschaften und -technologien, Technische Universität Berlin, Ernst-Reuter-Platz 1, 10587 Berlin, Germany

Ch. Genzel · A. R. Pyzalla

Helmholtz-Zentrum Berlin für Materialien und Energie (c/o BESSY), Albert-Einstein-Straße 15, 12489 Berlin, Germany 


\section{Introduction}

The integrity and adherence to substrate of protective oxide scales are impaired by stress generation accompanying the growth of oxides $[1,2]$. These internal stresses consist of an intrinsic part resulting from growth incompatibilities during oxidation and, as metallic work pieces are often subjected to start-up and shutdown conditions, of an extrinsic part caused by the thermal-expansion mismatch between the oxide scale and the metallic substrate during thermal cycling between service and room temperature (RT).

\section{Growth Stresses in Oxide Scales}

Of the stress-generating mechanisms the thermal-expansion mismatch is well understood [1]. Regarding internal stress formation due to oxide growth, several mechanisms have also been proposed over the past years [3]. Among them, the volumetric change between the oxide formed and the metal consumed according to Pilling and Bedworth [4], the growth of new oxide in oxide grain boundaries [5-7] and epitaxial growth $[8,9]$ have been mostly reported to be the source of growth stresses. Apart from the description of epitaxial stresses, all existing stress generation theories assume oxide growth either by exclusively inward anion diffusion or by mixed fluxes of anions and cations along grain boundaries. According to this scheme of oxidation, an oxide scale mainly growing by outward cation diffusion should not develop any significant internal stress.

Owing to the diversity of mechanisms for stress generation in oxide scales, the modeling of its time evolution has been possible only for cases where an individual oxide phase grows on the metallic substrate $[10,11]$ and the growth stresses are mainly attributed to strain sources located at oxide grain boundaries perpendicular to the interfaces. The applicability of those approaches is only limited to oxidation cases where multi-phase oxide scales grow, with metal as well as oxygen having different mobilities within each different oxide phase. Such is the case, for instance, of iron-based materials that evolve three-fold oxide scales, i.e. three layers of oxide each of a different phase, during oxidation at temperatures above $570{ }^{\circ} \mathrm{C}[12,13]$.

So far, the evolution of growth stresses in iron oxide scales has mostly been determined at low temperatures (i.e. $<570{ }^{\circ} \mathrm{C}$ ), where the mixed diffusion of anions and cations along oxide grain boundaries prevails over the outward bulk diffusion of iron cations in magnetite $[14,15]$. Under these conditions, only compressive stresses evolve in the oxide scale. However, results obtained for high temperature oxidation of iron-based alloys [16, 17] indicate tensile growth stresses in the oxide scale. The influence of possible orientation relationships between the iron oxides and the substrate also remains unclear since the existing stress studies deal exclusively with polycrystalline iron substrates.

\section{Aim of the Work}

We therefore aimed at shedding light on the complex stress situation in oxide scales growing on pure iron. The present work deals with iron oxides forming in 
atmospheric air at $650{ }^{\circ} \mathrm{C}$, i.e. above the wüstite formation point $\left(570{ }^{\circ} \mathrm{C}\right)$. The situation within the low-temperature oxidation regime of $\alpha$-iron, i.e. at $450{ }^{\circ} \mathrm{C}$, is treated in [18].

In order to infer the effect of substrate orientation and preferential orientation of oxide growth on the internal stress state, the present investigations concentrate on the oxidation behavior of iron single crystals with (110) surfaces. Energy-dispersive (ED) X-ray diffraction (XRD) with synchrotron radiation is applied to in situ stress analyses and ex situ texture studies of the oxide scales. In contrast to timeconsuming angle-dispersive (AD) diffraction experiments, the ED mode provides complete diffractograms for fixed sample and detector positions, considerably reducing the data acquisition times [19-21]. Grazing-incidence XRD in the traditional AD mode was performed ex situ to assess the effect of sample cooling on the depth gradients of the internal stresses. The link between microstructure and internal stresses is provided by scanning electron microscopy (SEM) and electron backscatter diffraction (EBSD) investigations.

\section{Experimental Details}

\section{Ex Situ Oxidation and Thermogravimetry}

Single crystals of pure iron with (110) surfaces were supplied with $4 \mathrm{~N}$ purity by Mateck GmbH, Jülich, Germany. The as-received iron single crystals were discs of $8 \mathrm{~mm}$ diameter and $1 \mathrm{~mm}$ thickness. The sample surfaces were polished with a roughness of $<0.03$ micron and an orientation accuracy of $<0.1^{\circ}$. Samples for ex situ diffraction and microstructure studies were oxidized at $650{ }^{\circ} \mathrm{C}$ in artificial air $\left(20 \% \mathrm{O}_{2} ; 80 \% \mathrm{~N}_{2}\right)$ at ambient pressure using a Setaram TGA 92 thermal balance. The heating rate was $1.5 \mathrm{~K} / \mathrm{s}$. The holding time at $650{ }^{\circ} \mathrm{C}$ after the heating-up phase was varied: $1 \mathrm{~s}, 1 \mathrm{~h}, 2 \mathrm{~h}, 5 \mathrm{~h}$, and $10 \mathrm{~h}$.

For the sake of comparison, the oxidation kinetics were determined for an iron single crystal with (110) surface and a polycrystalline Armco iron sample. The hotrolled pure iron polycrystal (Armco-iron) was supplied by REMAG AG, Mannheim, Germany. Its chemical composition is provided in [18]. The average grain size is $25 \mu \mathrm{m}$. The sample surface of the oxidized polycrystal was prepared by grinding and polishing with SiC-paper and diamond paste. Colloidal silica with $0.25 \mu \mathrm{m}$ grain size was used as a final polishing stage.

Microstructure and Texture Studies

\section{Sample Preparation}

After oxidation the specimens were sputtered with gold and nickel (15 $\mu \mathrm{m}$ layer thickness) to protect the oxide scale during mechanical preparation and to enhance the electrical conductivity around the oxides. Sample cross-sections were prepared by grinding with $\mathrm{SiC}$-paper (600-4,000 grit), then lapping with diamond films $(6,3$, $1,0.1 \mu \mathrm{m})$, and final polishing with colloidal silica. 


\section{$E B S D$}

The oxide layers were characterized using a SEM JEOL JSM6490 equipped with a TSL-EBSD system. All EBSD maps were analyzed with respect to phase identification, grain size distribution and crystallographic texture using the OIM 5.22 software.

\section{ED Diffraction Studies}

Texture formation in the hematite layer and the evolution of growth stresses during oxidation at $650{ }^{\circ} \mathrm{C}$ were investigated by ED diffraction at the Materials Science Beamline EDDI of the Helmholtz Zentrum Berlin at the synchrotron storage ring BESSY [19, 20].

In ED diffraction the polychromatic white radiation originally obtained from the synchrotron photon source is used as the primary beam. Thus, for each diffractometer setting, all diffraction lines are generated simultaneously by different radiation energies at a fixed diffraction angle $2 \theta$. Details of the experimental set-up and the measurement technique were published in [18].

The result of a ED diffraction measurement is therefore a diffractogram containing the diffraction lines of all phase constituents as a function of the energy. Figure 1 displays a typical ED diffractogram of the iron oxide scale growing at $650{ }^{\circ} \mathrm{C}$. The acquisition time for recording such an entire ED diffractogram at a certain $\psi$-tilt was only $2.5 \mathrm{~min}$. At the EDDI beamline all evaluable diffraction lines lie between 15 and $85 \mathrm{keV}$, which corresponds to the energy range of highest photon fluxes [19]. For the present investigations the $2 \theta$-position was fixed at $8^{\circ}$ and the symmetric diffraction geometry was applied as described in [18]. Considering

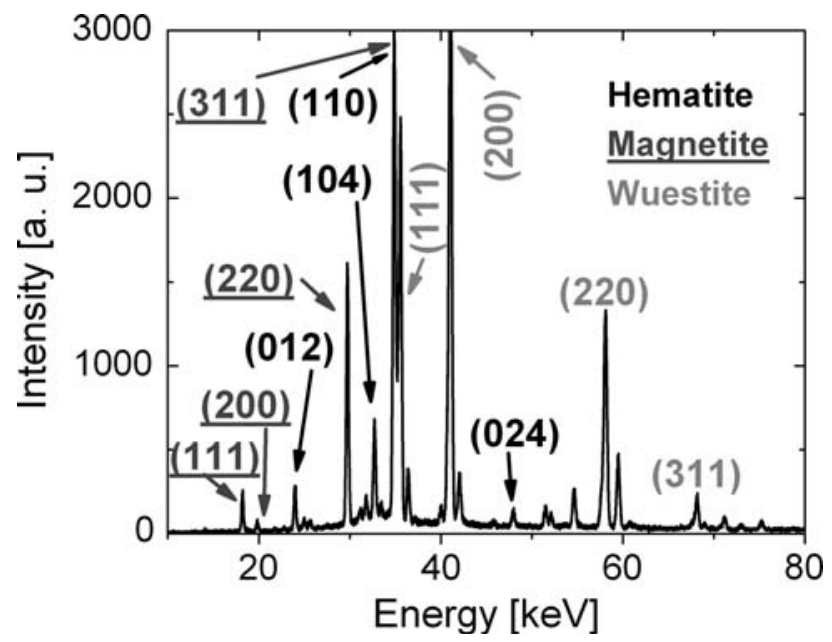

Fig. 1 Typical energy-dispersive synchrotron X-ray diffractogram of the iron oxide scale growing at $650{ }^{\circ} \mathrm{C}$ 
the available energy range of $15-85 \mathrm{keV}$, the average penetration depth into the iron oxide scale amounts to $45 \mu \mathrm{m}$.

The gauge volume was defined by primary slits of $1 \times 1 \mathrm{~mm}^{2}$ and secondary slits of $30 \mu \mathrm{m} \times 5 \mathrm{~mm}$. The position of the sample surface was realigned after each analysis by measuring the diffracted intensity, when moving the sample across the gauge volume. Because of the coarse grain size in the wüstite sub-layer, the sample was translated parallel to the sample surface during the experiment in order to enhance the measurement statistics.

\section{X-Ray Texture Analysis}

Texture analysis of the thin topmost hematite layer could only be performed by ex situ ED diffraction due to experimental difficulties associated with the metallographic preparation of the brittle iron oxide layers. ED diffraction allowed the simultaneous measurement of the (012), (104), (116), and (119) pole figures of hematite. The orientation distribution function (ODF), inverse and calculated pole figures were computed using the BEARTEX software [22].

\section{In Situ Stress Studies}

The in situ oxidation experiment for stress determination was carried out at $650{ }^{\circ} \mathrm{C}$ in atmospheric air using an air-cooled resistance furnace developed in-house, which enables heating-up rates of $1,000 \mathrm{~K} / \mathrm{min}$ and stable temperatures of up to $1,000{ }^{\circ} \mathrm{C}$. The temperature remained constant within $\pm 10^{\circ} \mathrm{C}$. ED diffractograms were recorded at a fixed $2 \theta$-angle of $8^{\circ}$ for $9 \psi$-tilts between $18^{\circ}$ and $72^{\circ}$ and the phase-specific stresses were evaluated by averaging the stress values determined from the available diffraction lines with the $\sin ^{2} \psi$-method [23]. Considering the motor movements, $30 \mathrm{~min}$ were required for performing an entire $\sin ^{2} \psi$ measurement.

\section{Ex Situ Analysis of Residual Stresses and Their Gradients}

After performing the in situ oxidation experiment, the average residual stresses (RS) at RT were also determined by ED diffraction according to the $\sin ^{2} \psi$-method [23], but using $32 \psi$-tilts between $10^{\circ}$ and $74^{\circ}$.

Residual stress depth-profiling was carried out at the Beamline G3 of the Hamburger Synchrotron Radiation Laboratory HASYLAB by AD diffraction using a monochromatic synchrotron $\mathrm{X}$-ray radiation of $6.9 \mathrm{keV}$. The presumably undamaged hematite and magnetite layers grown after heating-up to $650{ }^{\circ} \mathrm{C}$, holding for $1 \mathrm{~s}$ and cooling down to RT were investigated based on the modified $\sin ^{2} \psi$-method realized in the combined $\omega / \psi$ mode. For details regarding the method the reader is referred to [24-28].

The penetration depth $\tau$ into an infinitely thick sample in this measurement geometry is given by: 


$$
\tau=\frac{\sin \omega \cdot \sin (2 \theta-\omega) \cdot \cos \psi}{\mu[\sin \omega+\sin (2 \theta-\omega)]}
$$

where $\omega, \theta$ and $\psi$ are the angles of a four-circle diffractometer and $\mu$ is the linear absorption coefficient. As in the case of thin oxide scales the penetration depth given by Eq. 1 may become much larger than the scale thickness, the concept of effective information depth $\tau^{\text {eff }}$ was established to define the depth into a thin film from which the diffraction information comes [29]:

$$
\tau^{\text {eff }}=\frac{\int_{0}^{\mathrm{D}} \mathrm{z} \cdot \mathrm{e}^{-\frac{z}{\tau}} \mathrm{d} z}{\int_{0}^{\mathrm{D}} \mathrm{e}^{-\frac{z}{\tau}} \mathrm{d} z}=\tau-\frac{\mathrm{De}^{-\frac{\mathrm{D}}{\tau}}}{1-\mathrm{e}^{-\frac{\mathrm{D}}{\tau}}}
$$

where $\tau$ is the penetration depth given by Eq. 1 and D is the layer thickness.

Thus, different effective information depths were achieved within the oxide sublayers by varying the instrumental angles $\omega$ and $\psi$ : $\omega$ from $0.2^{\circ}$ to $15^{\circ}$ and $\psi$ from $0^{\circ}$ to $72^{\circ}$. The asymmetric $\sin ^{2} \psi$-method under grazing incidence was applied to the (422) reflection of magnetite at $2 \theta \sim 63.2^{\circ}$ and the (104) of hematite at $2 \theta \sim 38.8^{\circ}$. This enabled to probe a range of $3 \mathrm{~nm}$ to $5 \mu \mathrm{m}$ penetration depth within the iron oxide scale.

\section{Results}

\section{Oxidation Kinetics}

The oxidation temperature $650{ }^{\circ} \mathrm{C}$ was reached after $6.5 \mathrm{~min}$ in the thermal balance. Figure 2 compares the square of the mass gain as a function of the oxidation time for an (110) oriented $\alpha$-iron single crystal and polycrystalline Armco iron. The oxidation kinetics in both cases are nearly parabolic. The approximate parabolic-rate constant $k_{\mathrm{p}}$ determined from the slope of the curves in Fig. 2 is $1.14 \times 10^{-9} \mathrm{~g}^{2} \mathrm{~cm}^{-4} \mathrm{~s}^{-1}$ for the iron single crystal and $1.06 \times 10^{-9} \mathrm{~g}^{2} \mathrm{~cm}^{-4} \mathrm{~s}^{-1}$ for the iron polycrystal. The oxide scale thicknesses determined on cross-sections of oxidized iron single crystals after different oxidation times are listed in Table 1.

Characterization of Microstructure and Texture in the Iron Oxide Scales Grown at $650{ }^{\circ} \mathrm{C}$

\section{Iron Oxide Phases}

The microstructure of the oxide scales was characterized on sample cross-sections by SEM and EBSD after $1 \mathrm{~s}, 1 \mathrm{~h}, 5 \mathrm{~h}$ and $10 \mathrm{~h}$ oxidation in the thermal balance (Figs. 3, 4). After heating-up to $650{ }^{\circ} \mathrm{C}(6.5 \mathrm{~min})$, holding for $1 \mathrm{~s}$ and cooling down to RT, an oxide scale of $4.0 \mu \mathrm{m}$ thickness grows on the iron substrate. It mainly consists of a magnetite $\left(\mathrm{Fe}_{3} \mathrm{O}_{4}\right)$ layer. A discontinuous wüstite $\left(\mathrm{Fe}_{1-\mathrm{x}} \mathrm{O}\right)$ layer a few 


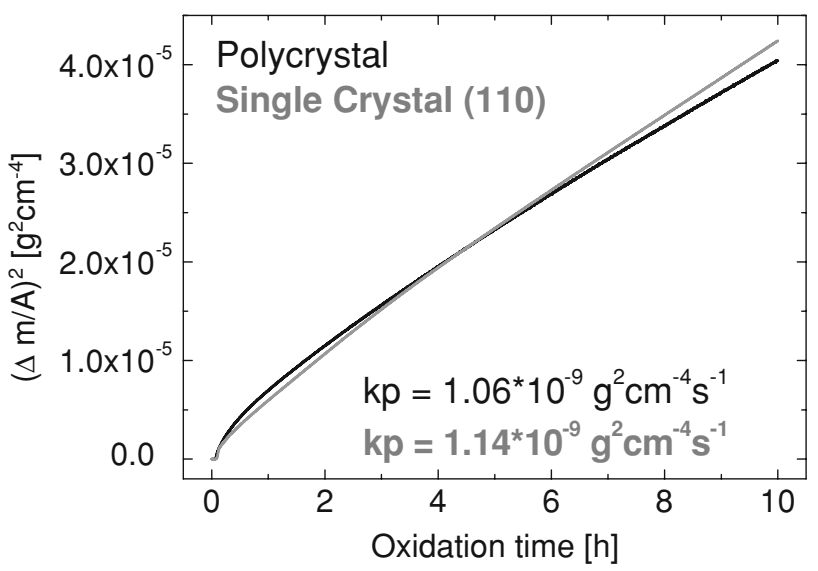

Fig. 2 Square of the mass gain of an iron single crystal with (110) surface and an Armco iron polycrystal during oxidation in artificial air at $650{ }^{\circ} \mathrm{C}$ as a function of the oxidation time and the corresponding temperature cycle

Table 1 Thicknesses of the iron oxide scale after different oxidation times at $650{ }^{\circ} \mathrm{C}$ in artificial air at ambient pressure using the thermal balance

\begin{tabular}{lllll}
\hline Scale thickness $(\mu \mathrm{m})$ & & & \\
\hline $1 \mathrm{~s}$ & $1 \mathrm{~h}$ & $2 \mathrm{~h}$ & $5 \mathrm{~h}$ & $10 \mathrm{~h}$ \\
\hline $4.1 \pm 0.4$ & $18.3 \pm 0.7$ & $26.5 \pm 0.2$ & $48.4 \pm 0.6$ & $64.0 \pm 0.6$ \\
\hline
\end{tabular}

nanometers thick grows at the interface with the substrate, whereas hematite $\left(\mathrm{Fe}_{2} \mathrm{O}_{3}\right)$ is formed on top of the oxide scale. However, hematite can only be locally identified by indexing Kikuchi-patterns recorded at the topmost regions of the oxide scale (Fig. 3). With ongoing oxidation, wüstite is observed to grow much faster than the magnetite and hematite layers. The thickness of the wüstite sub-layer reaches $13 \mu \mathrm{m}$ after $1 \mathrm{~h}$ and $58 \mu \mathrm{m}$ after $10 \mathrm{~h}$ of oxidation, whereas magnetite is only $5 \mu \mathrm{m}$ and hematite only $1 \mu \mathrm{m}$ thick after $10 \mathrm{~h}$.

The grain morphology becomes columnar with increasing oxidation times in magnetite and in the rapidly growing wüstite layer, whereas it remains equiaxial in hematite. The average grain size of wüstite increases considerably from $30 \mu \mathrm{m}^{2}$ after $1 \mathrm{~h}$ to $180 \mu \mathrm{m}^{2}$ after $10 \mathrm{~h}$. In magnetite it grows slowly from $4 \mu \mathrm{m}^{2}$ after $1 \mathrm{~h}$ to $7 \mu \mathrm{m}^{2}$ after $10 \mathrm{~h}$.

SEM studies (Fig. 4) further reveal that the iron oxide scale initially grows intact on the iron single crystal. After $1 \mathrm{~h}$ of oxidation micro-voids appear primarily within the magnetite layer and at the wüstite/substrate interface. Figure 5 displays in addition that, above regions of void coalescence at the interface with the substrate, a significant concentration of pores occurs in the wüstite layer, indicating that the wüstite could have been consumed in those locations. With increasing oxidation time, the porosity of the magnetite layer remains, whereas the average number of micro-voids increases considerably in the upper wüstite regions. After $10 \mathrm{~h}$ the 


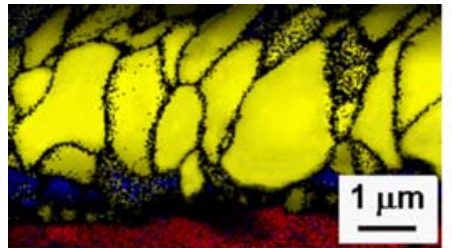

$1 \mathrm{~s}$

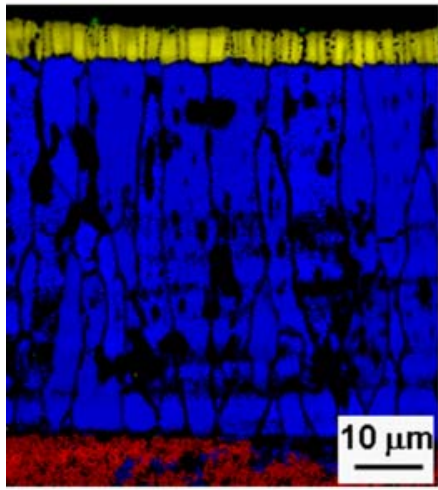

$10 \mathrm{~h}$

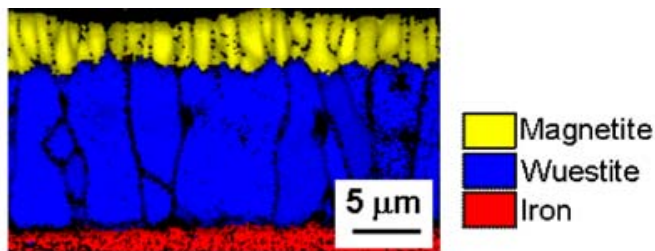

$1 \mathrm{~h}$

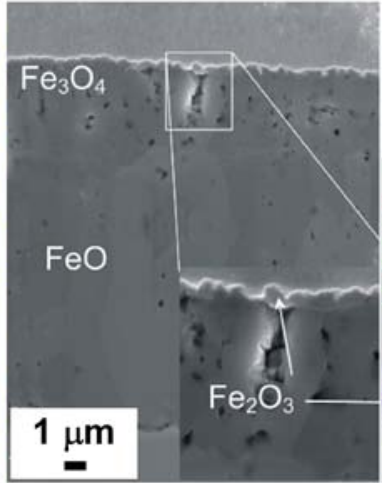

Hematite

Fig. 3 Evolution of phase composition (EBSD) in the oxide scale during oxidation at $650{ }^{\circ} \mathrm{C}$

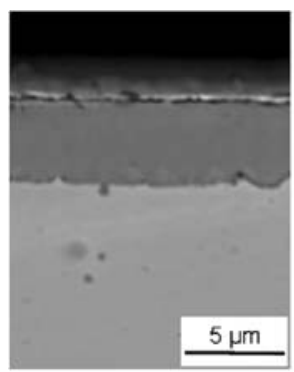

1s

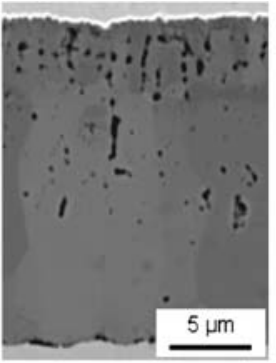

$1 \mathrm{~h}$

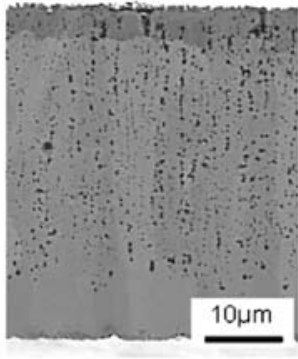

$5 \mathrm{~h}$

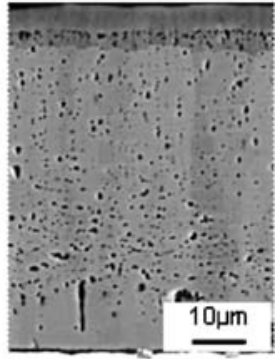

$10 \mathrm{~h}$

Fig. 4 Scale cross-sections (SEM) as a function of the oxidation time

porosity further increases within the wüstite layer towards its interface with the substrate.

Through scale cracking or layer spallation could not be observed for any of the investigated oxidation times. Figure 6 shows, however, that micro-cracking occurs in the direction perpendicular to the surface and interfaces, but it is mostly confined to the wüstite bottom layer.

\section{Texture}

Figure 7 shows the pole figures of magnetite and wüstite as well as the orientation of the iron single crystal substrate obtained by EBSD after $5 \mathrm{~h}$ of oxidation at 

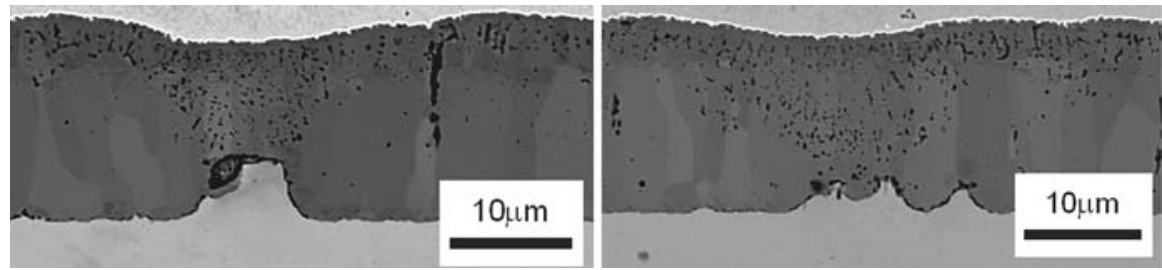

Fig. 5 Increased porosity in the wüstite layer after $1 \mathrm{~h}$ of oxidation occuring above regions of void coalescence at the interface with the substrate. As a result, wüstite appears to be consumed in order to further enable the growth of magnetite and hematite

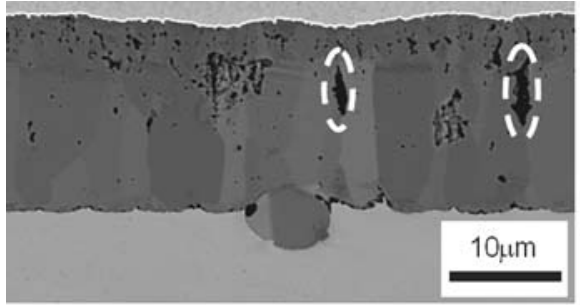

$1 \mathrm{~h}$

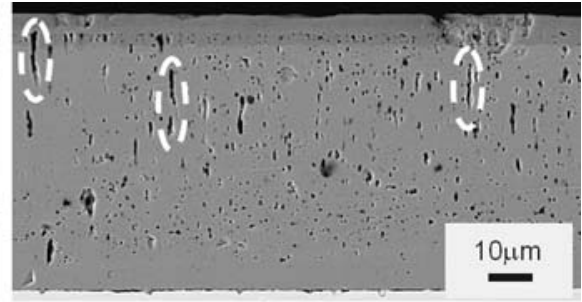

$10 \mathrm{~h}$

Fig. 6 Isolated crack-like voids with an orientation perpendicular to the scale surface occurring preferentially in the wüstite bottom layer

$650{ }^{\circ} \mathrm{C}$. Wüstite and magnetite evolve clear $\{001\}$ fibre textures parallel to the $\{110\}$ surface normal of the iron substrate (Fig. 7) and there is no clear evidence of an in-plane orientation relationship between wüstite, magnetite and the iron single crystal substrate. The preferential orientation of growth for wüstite and magnetite does not change with the oxidation time. ED diffraction revealed furthermore that hematite, on top of the scale, develops after $10 \mathrm{~h}$ of oxidation multiple fibre components (Fig. 8), which are even weaker than those determined in magnetite and wüstite.

\section{Phase-Specific d- $\sin ^{2} \psi$ Distributions and Determination of DECs}

Figure 9a shows typical ED diffractograms of the oxide layer growing at $650{ }^{\circ} \mathrm{C}$. Despite the fiber texture observed in the magnetite and wüstite sub-layers, sufficient intensity was diffracted for all the observed reflections of wüstite, magnetite and hematite up to the highest $\psi$-angles. This allowed for unrestricted lattice spacing measurements as a function of $\sin ^{2} \psi$.

In order to infer the characteristics of the $d-\sin ^{2} \psi$-distribution for each of the iron oxides composing the oxide scale lattice spacing measurements were carried out every $2^{\circ}$ up to a $\psi$-angle of $74^{\circ}$ after cooling samples from the oxidation temperature down to RT. Figure $9 \mathrm{~b}$ displays typical $\sin ^{2} \psi$-curves obtained by EDXRD at RT.

Hematite as well as magnetite exhibit fairly linear $\sin ^{2} \psi$-curves. The $\sin ^{2} \psi$ curves of wüstite, on the other hand, are characterized by a certain random 

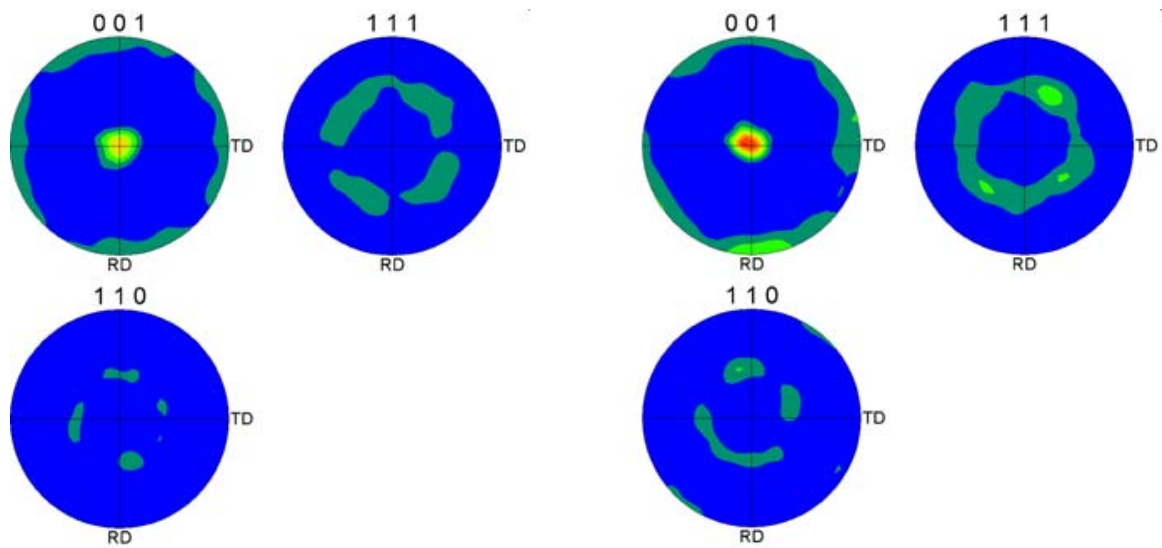

Wüstite
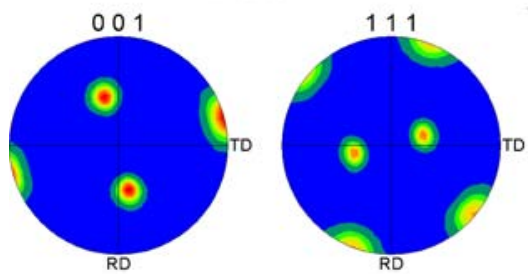

Magnetite

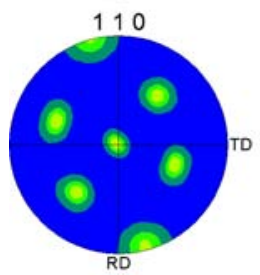

Iron

Fig. 7 Pole figures of magnetite and wüstite, and orientation of iron substrate for $5 \mathrm{~h}$ of oxidation at $650{ }^{\circ} \mathrm{C}$

scattering about the fitted lines. Systematic oscillations, however, were not observed, as it may occur in thin films with fiber texture [30, 31]. This is in accordance with the elastic isotropy of wüstite reported in [32]. The random nonlinearities observed in the $d$ - $\sin ^{2} \psi$-distributions of wüstite characterize an effect of coarse grains, which is corroborated by our microstructure characterization. This leads to the need to translate the samples during stress analyses and it increases the uncertainties in the stress values of wüstite with decreasing stress levels.

Due to the columnar oxide growth and the linear d- $\sin ^{2} \psi$-distributions observed, grain interaction in the iron oxide scale was thus assumed to be best described using the Reuss approach [33, 34]. Under this assumption, the phase-specific diffraction elastic constants (DEC) were evaluated using the single crystal elastic constants available for RT in [35] for magnetite and hematite, and in [36] for wüstite. 

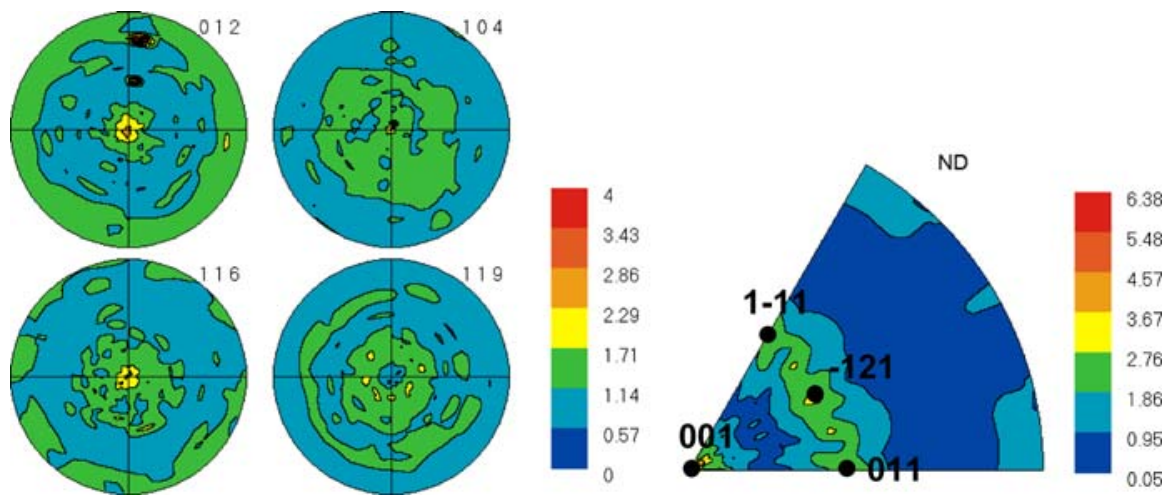

Fig. 8 Pole figures of hematite and inverse pole figure corresponding to the surface normal direction
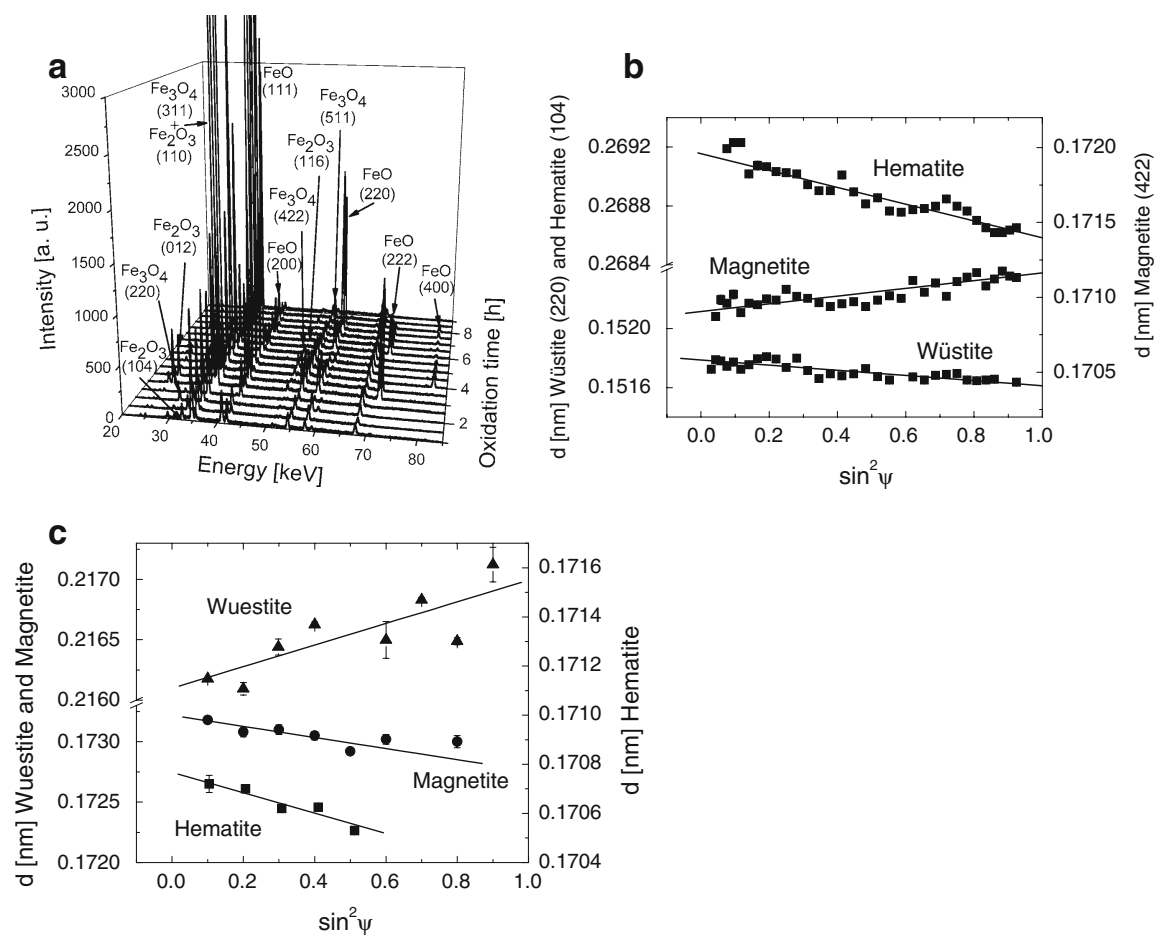

Fig. 9 Energy-dispersive synchrotron X-ray diffractograms from the growing iron oxide layer recorded during oxidation at $650{ }^{\circ} \mathrm{C}$ for $10 \mathrm{~h}$ (a). Typical $\mathrm{d}$ - $\sin ^{2} \psi$-curves for the residual stress analysis after cooling down (b), and during in situ stress analyses (c)

\section{In Situ Stress Analysis by ED Diffraction}

The penetration depth of the white beam into the iron oxides $(45 \mu \mathrm{m})$ is much larger than the maximum thicknesses of the upper hematite and magnetite sub-layers 
(1.0 and $8.0 \mu \mathrm{m}$, respectively). Thus, the stress values of hematite and magnetite given in Fig. 10 are representative averages for their layer thicknesses during the entire experiment.

In contrast, the wüstite layer reached $150 \mu \mathrm{m}$ at the end of the in situ oxidation cycle. Assuming that the oxidation kinetics is described by a single parabolic stage, the thickness of the wüstite layer is estimated to be about $50 \mu \mathrm{m}$ after $1 \mathrm{~h}$ of oxidation, i.e. at the end of the first $\psi$-scan. This implies that the $45 \mu$ m penetration depth comprised the entire wüstite layer only during the first stress analysis. With ongoing oxidation the location, where the stress values of wüstite come from, represent a $45 \mu \mathrm{m}$ region beneath the magnetite/wüstite interface, as indicated in Fig. 10a. As a result, the last stress analysis performed after $9 \mathrm{~h}$ of oxidation provides information from the upper third of the innermost wüstite layer.

In addition, the increase of layer thickness $\Delta \mathrm{x}$ for the fastest growing wüstite during a $30 \mathrm{~min} \sin ^{2} \psi$-analysis decreases with time owing to the parabolic nature of the oxidation kinetics $\left(\Delta \mathrm{x}_{30 \text { min }}=\sqrt{\mathrm{k}_{\mathrm{x}}} / 4 \cdot \mathrm{t}^{-1 / 2}\right.$ with $\mathrm{k}_{\mathrm{x}} \approx 2.5 \times 10^{3} \mu \mathrm{m}^{2} \mathrm{~h}^{-1}$ as the parabolic constant for wüstite thickness growth). Accordingly, the maximum increase of wüstite layer thickness is of only $18 \mu \mathrm{m}$ during the first $\sin ^{2} \psi$-analysis. After e.g. $2 \mathrm{~h}$ of oxidation the thickness increase amounts to only $9 \mu \mathrm{m}$, whereas it is simply $4 \mu \mathrm{m}$ past $9 \mathrm{~h}$. These values fall into the positioning accuracy of a diffractometer, which is given by its sphere of confusion (typically in the order of tens of microns) [37-39]. These observations indicate therefore that the continuous increase of scale thickness during each stress analysis has only a minor influence on the accuracy of the in situ stress evaluation procedure.

Typical $\sin ^{2} \psi$-curves obtained during the in situ experiment at $650{ }^{\circ} \mathrm{C}$ are shown in Fig. 9c. Figures $10 \mathrm{~b}$ and 11 display the time evolution of the growth stresses for the three iron oxides during $10 \mathrm{~h}$ of oxidation. Each individual stress value in these figures was obtained by averaging the results of the $\sin ^{2} \psi$-analyses performed for all diffraction lines assessable (indicated for each iron oxide in Figs. 10b and 11).

The results reveal time-dependent stress cycles for magnetite and the upper part of the wüstite layer. The trends for the two inner sub-layers during the first $4 \mathrm{~h}$ of oxidation are, however, opposite. Magnetite evolves tensile stresses of about
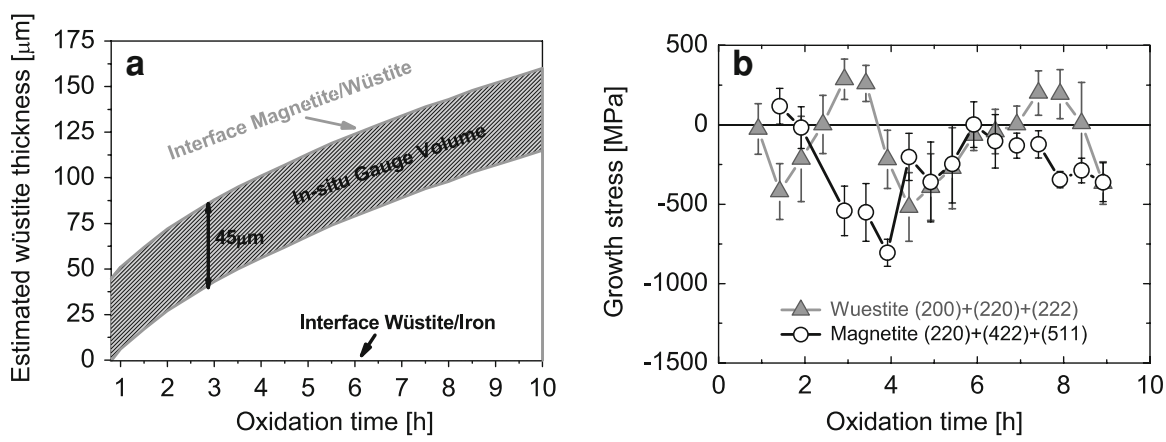

Fig. 10 (a) Evolution of wüstite layer thickness and location of gauge volume within the wüstite layer during the in situ oxidation experiment at $650{ }^{\circ} \mathrm{C}$; (b) time evolution of average internal stresses in wüstite and magnetite during oxidation 


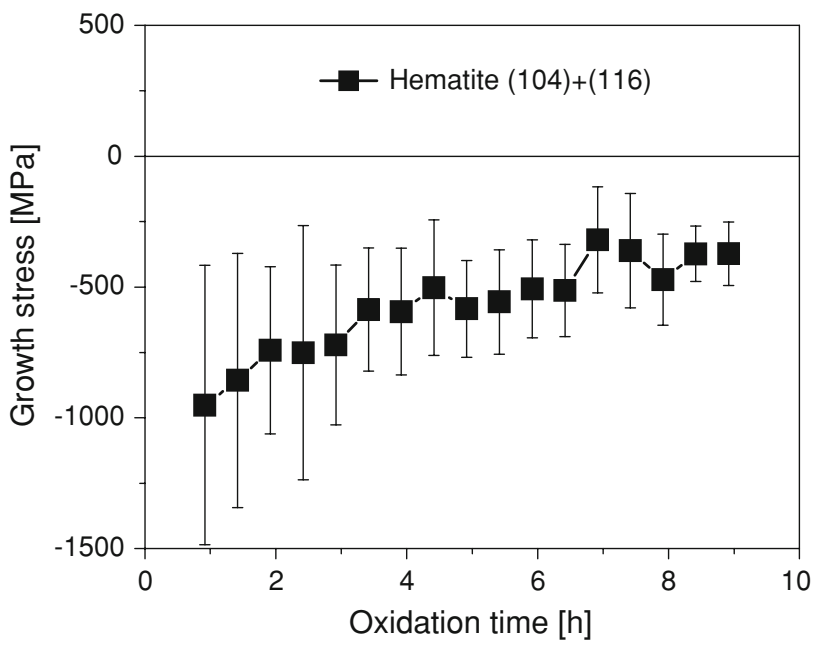

Fig. 11 Time evolution of average internal stresses in hematite during oxidation

$+100 \mathrm{MPa}$ during the first $50 \mathrm{~min}$. With ongoing oxidation, these initial tensile stresses decrease. After $2.5 \mathrm{~h}$ of oxidation at $650{ }^{\circ} \mathrm{C}$ the magnetite layer already undergoes $-500 \mathrm{MPa}$ compressive stresses, which continue to increase up to $-800 \mathrm{MPa}$ after $4 \mathrm{~h}$. At this point, the compressive stress state starts to release gradually until $6 \mathrm{~h}$, where increasing compression evolves in magnetite once again.

Within the $45 \mu \mathrm{m}$ region beneath the interface with magnetite, wüstite initially evolves increasing compressive stresses, which after $1.5 \mathrm{~h}$ start to turn into tensile stresses. Maximum tensile stresses of about $+300 \mathrm{MPa}$ are observed after $3 \mathrm{~h}$. These tensile stresses change afterwards into compression, reaching a maximum of $-500 \mathrm{MPa}$ after $4 \mathrm{~h}$. The cyclic stress behavior persists with tensile stresses growing during the next $1.5 \mathrm{~h}$ up to $+200 \mathrm{MPa}$ and compressive stresses evolving again after $8 \mathrm{~h}$.

The topmost hematite layer does not show any periodic stress variation. It undergoes high compressive stresses of nearly -1,000 MPa during the first $50 \mathrm{~min}$ of oxidation. Its compressive stress state persists for $10 \mathrm{~h}$, however, continuously easing with ongoing oxidation.

Residual Stresses in the Oxide Layers After Cooling to Room Temperature

\section{Average Residual Stresses}

Figure 12 compares the last growth stress values determined at $650{ }^{\circ} \mathrm{C}$ with the residual stresses obtained after cooling the in situ sample down to RT. At the end of the in situ oxidation cycle compressive growth stresses are observed in all three sublayers. Sample cooling leads the wuestite sub-layer to develop compressive stresses similar to those observed at $650{ }^{\circ} \mathrm{C}$, but hematite to compressive stresses, which are clearly lower than its high-temperature values. In contrast to wüstite and hematite, 


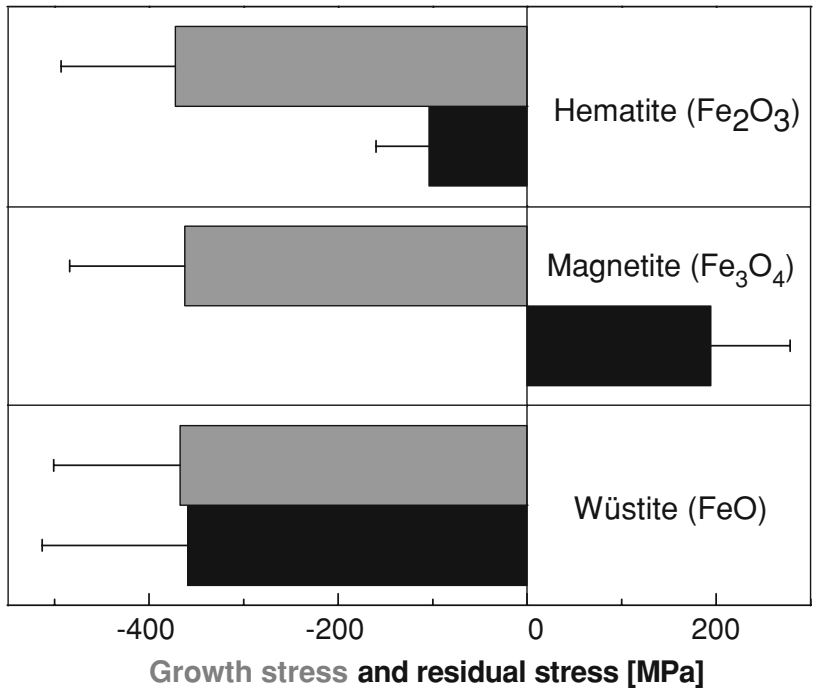

Fig. 12 Comparison between growth stress values at $650{ }^{\circ} \mathrm{C}, 10 \mathrm{~h}$ of oxidation ( grey bars) and the correspondent residual stresses after cooling (black bars) in hematite, magnetite and wüstite

the intermediate magnetite layer evolves tensile residual stresses of nearly $+200 \mathrm{MPa}$.

\section{Gradient of Residual Stresses}

In order to infer the spatial heterogeneity of the residual stresses across the oxide scale, phase-specific residual stress depth-profiles were determined for the undamaged two-phase oxide scale obtained after heating-up for $6.5 \mathrm{~min}$ until $650{ }^{\circ} \mathrm{C}$, holding for $1 \mathrm{~s}$ and cooling down to RT (Fig. 13) by grazing-incidence $\mathrm{XRD}$ using monochromatic radiation. The residual stresses are compressive in the 'bulk' of both, the magnetite and hematite sub-layers, but they gradually change into tensile stresses towards the interface with hematite and the free surface, respectively.

\section{Discussion}

Evolution of Microstructure and Texture in the Iron Oxide Scale

\section{Microstructure}

The oxide scales grown on iron single crystals with (110) surfaces at $650{ }^{\circ} \mathrm{C}$ were shown to develop a three-fold layer with a near-parabolic oxidation constant, which is very close to that of an iron polycrystal (Fig. 2). Oxidation at ambient (high) oxygen pressures causes the growth of the most oxygen-rich iron oxide, i.e. 


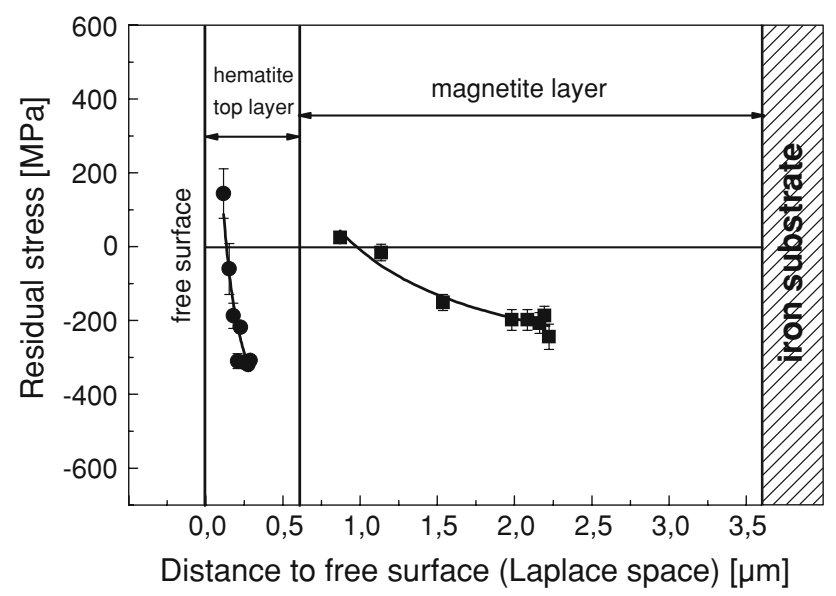

Fig. 13 Residual stress gradients in hematite and magnetite after heating the iron single crystal up to $650^{\circ} \mathrm{C}$, holding for $1 \mathrm{~s}$ and cooling down to RT inside the thermal balance

hematite, in contact with the atmosphere. The formation of hematite with a low defect density induces a gradient of oxygen partial pressure from the free surface towards the substrate. This leads to the formation of an intermediate layer of magnetite and a deepest one of wüstite with the lowest oxygen content next to the substrate. The same layer structure is also observed in oxidized iron polycrystals $[12,17,40,41]$.

The thickness of the hematite layer increases only very slowly from 0.5 to $1.0 \mu \mathrm{m}$ during $10 \mathrm{~h}$ of oxidation. During the heating-up stage magnetite evolves a $4.0 \mu \mathrm{m}$ thick layer, which remains nearly constant with proceeding oxidation. Wüstite starts growing only above $570{ }^{\circ} \mathrm{C}$. Its highly defective structure leads, however, to growth rates much faster than those observed for the higher iron oxides. Consequently, the relative thickness of the individual sub-layers is observed to vary during oxidation. The ratio of $\mathrm{FeO}: \mathrm{Fe}_{3} \mathrm{O}_{4}: \mathrm{Fe}_{2} \mathrm{O}_{3}$ changes from 74:23:3 after $1 \mathrm{~h}$ to 91:8:1 after $10 \mathrm{~h}$ of oxidation. These relative sub-layer thicknesses after $10 \mathrm{~h}$ are nearly the same as those reported for oxidized iron polycrystals ( 95:4:1) [41, 42].

\section{Porosity}

Porosity was observed to develop first in the magnetite layer. These pores can be caused by the predominant defect type in magnetite. It strongly depends on the oxygen partial pressure, changing from iron interstitials at low oxygen activities to iron vacancies at high oxygen activities [43, 44]. At ambient oxygen pressure magnetite is, therefore, expected to have a non-stoichiometric composition with iron vacancies. In order to maintain electroneutrality, the high oxygen activities cause high vacancy concentrations, which ultimately lead to pore formation. Another intrinsic mechanism of micro-voiding in magnetite was suggested in [6]. The vacancy mechanism of cationic lattice diffusion combined with the minor oxygen diffusion through uncharged vacancies creates conditions for magnetite 
consumption within the oxide scale. This represents a further source of voids in the magnetite sub-layer.

After long-term oxidation (Figs. 4 and 6,10h) the small pores growing initially in the magnetite layer appear to coagulate and form a row of coarser pores, which is oriented parallel to the surface and interfaces and located deep into the magnetite layer. This agrees with the predictions made by Tan et al. [43] that at high oxygen pressures pores appear within magnetite in locations far from the surface as a result of the displacement of the region, where iron has a minimum diffusion coefficient, towards the interface with the substrate.

At the wüstite/iron interface, iron cations move from the substrate into the wüstite layer, leading to an opposite flux of cation vacancies into the substrate [45, 46]. The process of vacancy injection necessarily leads to void formation, which decreases the effective area of mass transport between the iron substrate and wüstite. This is corroborated by our SEM studies, which revealed that porosity occurs at the wüstite/iron interface already after $1 \mathrm{~h}$ of oxidation. The reduction of contact area between wüstite and iron restricts the continuous supply of iron cations from the substrate towards the outer interfaces, where the following thermodynamic equilibria exist [42]:

$$
\begin{gathered}
\mathrm{Fe}^{2+}+2 \mathrm{e}^{-}+\mathrm{Fe}_{3} \mathrm{O}_{4} \Leftrightarrow 4 \mathrm{FeO} \text { magnetite/wustite interface } \\
\mathrm{Fe}^{\mathrm{n}+}+\mathrm{ne}^{-}+4 \mathrm{Fe}_{2} \mathrm{O}_{3} \Leftrightarrow 3 \mathrm{Fe}_{3} \mathrm{O}_{4} \text { hematite/magnetite interface }
\end{gathered}
$$

Consequently, the equilibria (3) and (4) are shifted to the left at the interfaces, leading magnetite and hematite to grow from wüstite. In addition, the inward migration of oxygen molecules until those interfaces, which is expected to occur in such porous oxide scales [47], increases the oxygen potential. This also favors the growth of the oxygen-richer iron oxides from wüstite. Both processes consume wüstite initially near to the interface with magnetite. With further oxidation, deeper wüstite regions start to be consumed as well. This causes increasing porosity in the wüstite bottom layer between 1 and $10 \mathrm{~h}$ of oxidation (Figs. 4, 5).

\section{Texture}

The (110) orientation of the iron single crystal substrates does not have a significant impact on the crystallographic texture of the individual oxide sub-layers. Magnetite and wüstite evolve only weak $\{001\}$ fibre textures, whereas hematite grows with several weak fibre components. $\{001\}$ fibres were also observed for magnetite and wüstite sub-layers grown on low carbon [48] and IF steels [49]. The $\{001\}$ crystallographic direction of wüstite and magnetite seems, therefore, to have the lowest surface energy, as suggested in [48], and governs the growth of these iron oxide sub-scales. This implies that epitaxial strains are not the major driving force for the growth of iron oxides at high-temperatures. The formation of multiple fibre textures in hematite was also previously observed after oxidation of polycrystalline iron-base materials [17]. It suggests that the development of the fibre axes in the early oxidation stages is associated with the orientations of the oxide nuclei and that the strength of each fibre depends on the growth rate in different crystallographic directions. 


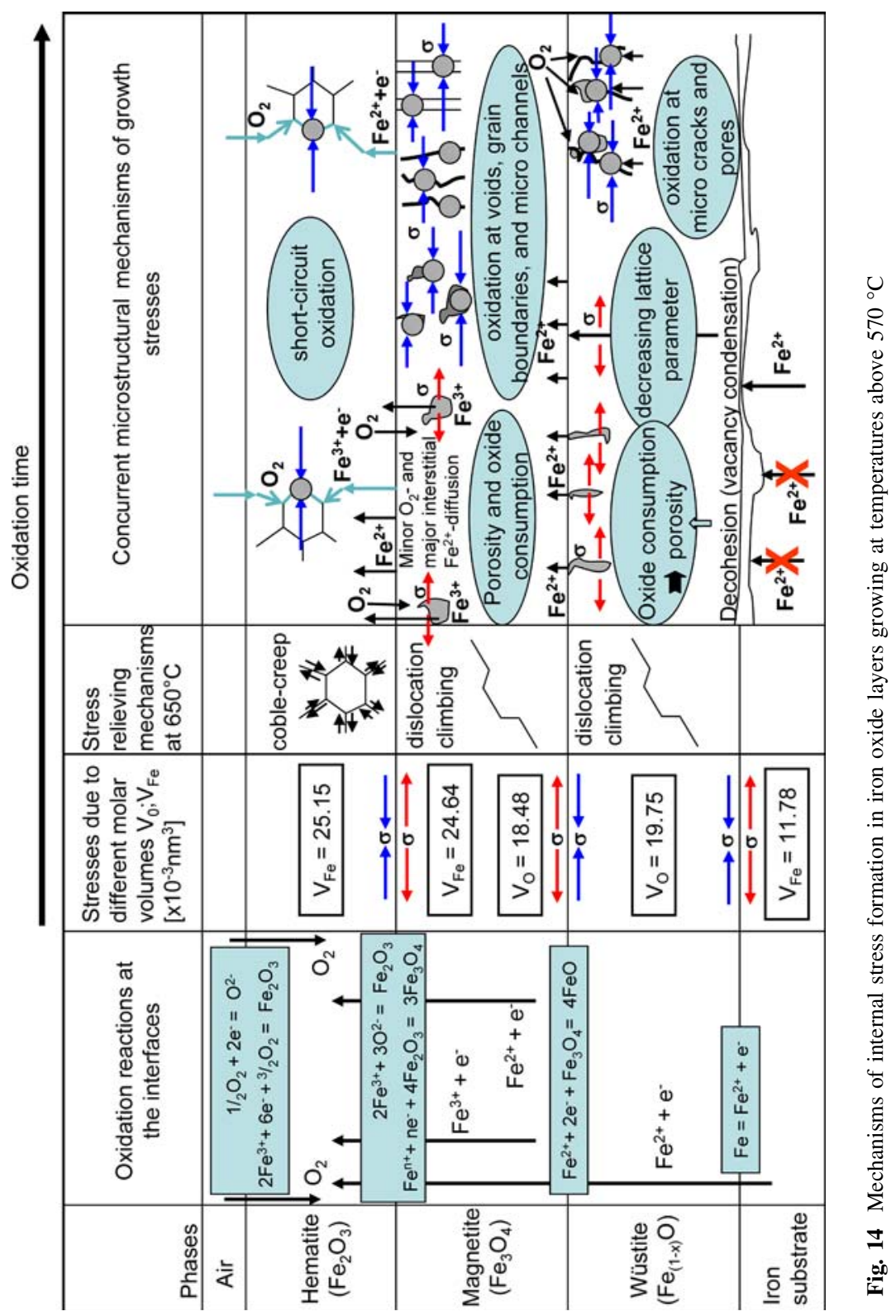




\section{Internal Stress Formation in Three-Fold Iron Oxide Scales}

The time-dependent stress cycles observed for magnetite and wüstite reflect diverse concurrent processes taking place during oxidation of iron at $650{ }^{\circ} \mathrm{C}$. Figure 14 schematically shows the microstructural mechanisms of stress formation in the individual iron oxide sub-layers.

\section{Initial Stress Situation}

The first stress values obtained after about $1 \mathrm{~h}$ of oxidation showed that magnetite initially grows under tensile stresses, whereas wüstite is subjected to increasing compression. Two mechanisms are able to induce tensile stresses in magnetite and compressive stresses in wüstite during the initial stages of oxidation. Epitaxial growth of magnetite on wüstite was proposed in [17] to be the source of tensile stresses in magnetite during $100 \mathrm{~h}$ of oxidation of mild steel. In this work, however, EBSD does not reveal any evident in-plane orientation relationship between neighboring wüstite and magnetite grains. Thus, the second, most likely, mechanism is the volumetric strain caused by differences in atomic volume between the first-formed grains of magnetite and wüstite. Although it has been shown that volumetric differences due to oxide growth are not the unique mechanism of internal stress formation [1-3], they are still reported to be a relevant cause of growth stresses in oxide scales [50-52].

However, iron is the rapidly diffusing specie through the magnetite/wüstite interface. A volumetric change in the iron lattice due to inward migration of oxygen ions, as in the model originally proposed by Pilling and Bedworth [4], is therefore not directly applicable to the magnetite/wüstite interface. Nevertheless, the cationic Pilling-Bedworth ratio (PBR) can be modified according to [53] for cases where cation diffusion is the major transport process, taking into account an unchanging oxygen lattice with mobile cations. Thus, an anionic volume ratio (AVR) can be defined for the magnetite/wüstite interface as $\mathrm{V}_{\mathrm{O}}\left(\mathrm{Fe}_{3} \mathrm{O}_{4}\right) / \mathrm{V}_{\mathrm{O}}\left(\mathrm{Fe}_{1-\mathrm{x}} \mathrm{O}\right)$, where $\mathrm{V}_{\mathrm{O}}$ represents the volume of the corresponding oxide per oxygen atom. [53] showed that in the present case the AVR amounts to 0.94. In accordance with our experimental data, an AVR of less than 1 predicts that magnetite, which has a smaller atomic volume, is subjected to tensile stresses, whereas wüstite undergoes compressive stresses. On top of the oxide scale, hematite has a greater atomic volume than magnetite [53], and its growth occurs predominantly by diffusion through short-circuit paths [13]. This rapidly leads to high compressive stresses in hematite during the early oxidation stages, but also supports the formation of tensile stresses in magnetite at its interface with hematite.

\section{Wüstite}

The long-term evolution of growth stresses in wüstite was observed to follow a trend, which is opposite to that encountered in magnetite. Considering that a region of $45 \mu \mathrm{m}$ thickness below the wüstite/magnetite interface was investigated, the results imply that the stress situation within this upper region of the wüstite layer is influenced by the growth of magnetite on it. 
SEM investigations revealed that the wüstite layer partially loses its contact to the substrate already after $1 \mathrm{~h}$ of oxidation (Fig. 4). As displayed in Fig. 5, wüstite is consumed in those regions of less contact with the substrate, causing shrinkage at the interface with magnetite. The cation-deficient wüstite comprises a composition range between the wüstite/iron and wüstite/magnetite interfaces. According to the $\mathrm{Fe}-\mathrm{O}$ phase diagram [41], the $\mathrm{Fe}: \mathrm{O}$ ratio of wüstite intrinsically decreases towards its outer interface with magnetite $[41,54]$ causing a gradient of defect concentration, which is fixed by the equilibrium oxygen activities at the interfaces with iron and with magnetite for any given temperature. This intrinsic gradient of stoichiometry can also reduce the volume of wüstite [55-59] with increasing distance to the iron substrate. Another factor affecting the internal stress situation in wüstite is dislocation creep at $650{ }^{\circ} \mathrm{C}[1,60]$.

Therefore, volumetric changes caused by oxide growth can be the origin of internal stress between magnetite and wüstite only during the initial oxidation stages where wüstite is still a relatively thin and adherent layer, allowing the continuous supply of iron cations from the substrate to the growth of the higher iron oxides. Afterwards, shrinkage induced by wüstite consumption as well as by gradients of stoichiometry leads to decreasing compression and increasing tensile stresses at the upper part of the wüstite layer.

After wüstite reaches a maximum tensile stress of $+300 \mathrm{MPa}$, a sudden drop into the compressive stress region is observed. This is in agreement with our SEM inspections which revealed in Fig. 6 that micro cracks evolve within the wüstite sub-layer. These small cracks can form micro channels through the scale, thus enabling the inward migration of oxygen molecules. Oxygen can then rapidly react with iron, closing the micro channels within the wüstite layer by inner oxide formation and causing, as a result, compressive stresses after $4 \mathrm{~h}$. This internal compression starts to be relieved after $5 \mathrm{~h}$ probably as a result of pore formation, since creep of wüstite is hampered by its long columnar grains oriented perpendicular to the growth stresses. The increasing porosity at the interface with magnetite produces tensile stresses after $7 \mathrm{~h}$, which once again cause damage and subsequent inner oxide growth. This introduces compressive stresses into wüstite at the end of the oxidation cycle.

\section{Magnetite}

The mixed flux of cations and anions along grain boundaries was shown to be a relevant transport process within this intermediate sub-layer [14], causing compressive growth stresses. Our microstructure studies further reveal void formation in magnetite since the early oxidation stages (Fig. 4). Thus, with ongoing oxidation, magnetite crystals grow within voids and grain boundaries, relieving the initial tensile stress state and causing internal compression. The stress evolution is opposite to that of wüstite, and a maximum compressive stress of $-800 \mathrm{MPa}$ is observed after $4 \mathrm{~h}$. In spite of the high compressive stress value, micro cracking can not be clearly observed in the magnetite layer. After prolonged oxidation (Figs. 4 and $6,10 \mathrm{~h}$ ) the magnetite layer exhibits a row of pores near the magnetite/wüstite interface, but its top part remains compact and crack-free. This observation agrees 
with the results presented by Buscail et al. [61, 62], where $30 \mu \mathrm{m}$ thick wüstite layers growing on pure iron substrates within the high-temperature oxidation regime $\left(800{ }^{\circ} \mathrm{C}\right)$ were capable of withstanding compressive stresses of more than $-1,000 \mathrm{MPa}$ for several hours.

Porosity can counterbalance compressive stresses in magnetite as suggested in the case of wüstite. Creep occurs in magnetite at $650{ }^{\circ} \mathrm{C}$ [63], favored by its small grains with nearly equiaxed shape. The inner compression is, therefore, observed to ease after $4 \mathrm{~h}$, most probably as a result of creep and voiding. Long-term creep further increases porosity at grain boundaries and causes intergranular failure [64]. Thus, micro channels are generated in the magnetite layer during creep, allowing for inward oxygen migration and internal oxide formation. This causes increasing compressive stresses after $6 \mathrm{~h}$ of oxidation.

\section{Hematite}

The initial compression in hematite eases with ongoing oxidation as a result of creep. However, stress relief occurs at rates much slower than those observed for magnetite and wüstite. This is in agreement with deformation mechanism maps [60], which predict that the strain rates in hematite are at least 3 orders of magnitude lower than in magnetite at $650{ }^{\circ} \mathrm{C}$.

The non-periodic stress behavior further suggests that, in contrast to the inner sub-layers, spalling and de-cohesion do not occur in the hematite layer during $10 \mathrm{~h}$ of oxidation. However, oxygen molecules need to penetrate the outmost hematite layer in order to enable the formation of new oxides in cracks and pores of the inner sub-layers, as it was discussed for wüstite and magnetite. Thus, if the hematite layer would remain fully intact, such inward oxygen migration would be rather unlikely. This suggests, in accordance with earlier observations made by Kofstad [64], that although there was no evidence of crack formation, porosity and micro channels develop in the outmost fine-grained layer as a result of creep deformation under the high compressive growth stresses observed.

\section{Residual Stress Formation in Three-Fold Iron Oxide Scales on Cooling}

The generally different thermal expansion coefficients of the substrate and the iron oxides cause the development of phase-specific thermal stresses on cooling from the oxidation temperature down to RT. These thermal stresses superpose the stress state existing at high-temperatures prior to cooling to build-up the residual stresses experimentally determined at RT.

Figure 15 provides the evolution of thermal stresses with temperature for the oxide scale grown for $10 \mathrm{~h}$ at $650{ }^{\circ} \mathrm{C}$, assuming a linear elastic behavior of both the oxide scale and the substrate. The thermal stresses were calculated based on the multilayer approach given in [1, 65], which takes into account the experimentally determined thicknesses of the individual oxide sub-layers.

From pure cooling effects, hematite and wüstite are expected to evolve compressive residual stresses which are higher for hematite than for wüstite. Magnetite, on the other hand, might develop low tensile stresses at RT depending on 
the level of compressive growth stresses existent prior to cooling. This can be understood in light of the abnormal temperature behavior of the thermal expansion coefficient of magnetite [66,67], which is caused by a change from the normal spinel structure at high-temperature to an inverse spinel structure existing at low temperatures.

The experimentally determined residual stresses in Fig. 12 reveal, in agreement with the stress calculations (Fig. 15), compressive stresses in hematite and wüstite as well as tensile stresses in magnetite. The residual stresses of hematite are also higher than those of wüstite. However, the experimental stress values for wüstite and hematite are significantly lower than those calculated. Since the calculations demonstrate the evolution of thermal stresses far beyond the mechanical strength of the iron oxides [68], micro-cracking is likely to occur on cooling, relieving the internal stress state in hematite and wüstite. The residual stresses of magnetite are, on the other hand, as high as the calculated value. This corroborates the results from the microstructure studies (Figs. 4, 6) that revealed no through scale cracking as well as a compact magnetite layer after $10 \mathrm{~h}$ of oxidation.

The residual stresses also change with the depth into the scale (Fig. 13). At lower temperatures, where diffusion and viscoplastic deformation are suppressed, internal stress gradients result from the abrupt changes of thermal expansion at the existing interfaces. In contrast to the stress state observed after the in situ oxidation experiment, the average residual stresses of magnetite grown on the shortly oxidized single crystal were of compressive nature. This results firstly from the absence of a continuous wüstite layer, which has a lower thermal expansion coefficient than magnetite, at the interface with the substrate. An epitaxial growth of magnetite on the iron single crystal, which may occur during the early oxidation stages [61, 62], would cause also higher compressive growth stresses capable of shifting the residual stress state of the magnetite into compression. Due to the fact that magnetite contracts less than iron, but more extensively than hematite, compressive stresses

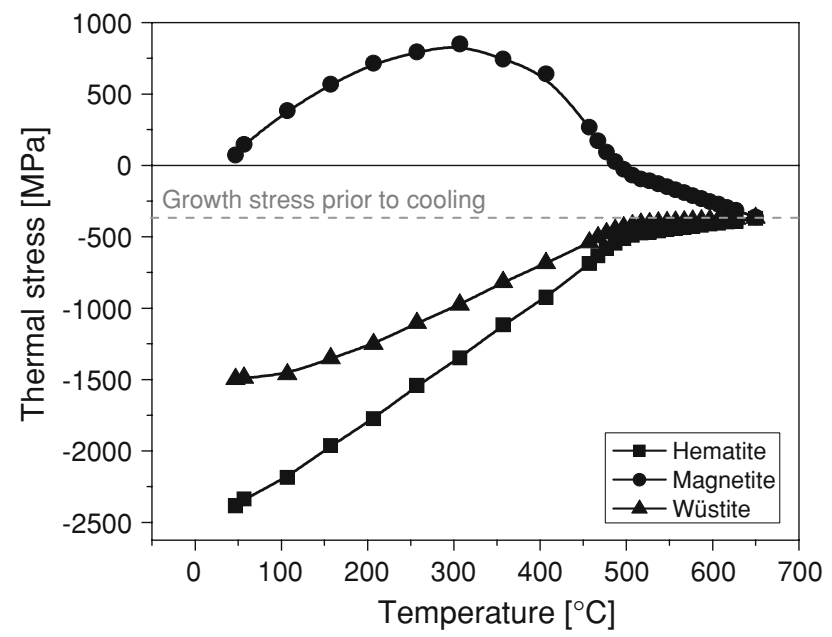

Fig. 15 Evolution of thermal stresses on cooling from $650{ }^{\circ} \mathrm{C}$ as a function of the temperature 
evolve at its interface with the substrate, whereas tensile stresses slowly grow towards the interface with hematite. Hematite can freely recede at the outer surface but its contraction is necessarily increased at the inner interface in to order to hold contact with the magnetite layer. This causes hematite to build-up compressive stresses near its interface with magnetite, but tensile stresses at the free surface.

\section{Conclusions}

We studied the evolution of microstructure and internal stresses in oxide scales growing on (110) surfaces of iron single crystals at $650{ }^{\circ} \mathrm{C}$ in order to determine the effect of substrate orientation and preferential orientation of oxide growth on the internal stress state of multiphase iron oxide scales.

EDXRD using synchrotron radiation demonstrated its potential for in situ studies of oxidation, allowing, for the first time, stress analyses in buried wüstite layers growing on iron substrates in atmospheric air at temperatures above $570{ }^{\circ} \mathrm{C}$.

The investigations revealed that:

- high-temperature oxidation of iron single crystals resulted in near-parabolic oxidation kinetics and scale microstructures, which do not significantly differ from those encountered in the oxidation of ferrous polycrystals;

- magnetite as well as wüstite develop weak $\{001\}$ fibre textures, whereas the thin topmost hematite layer shows several weak fibre components;

- stress analyses of the wüstite sub-layer are affected by its coarse microstructure. Enhanced measurement statistics require an increase in the number of diffracting crystallites using e.g. sample translations, angular oscillations or increased gauge volumes;

- owing to the weak texture in the entire iron oxide scale, epitaxial strains do not have a significant influence on the internal stress state of the individual sublayers. More relevant sources of growth stresses are volumetric differences between the iron oxide phases at the early oxidation stages, and later, new oxide formation within hematite and magnetite, wüstite consumption as well as pore formation in the magnetite layer;

- these microstructural mechanisms of stress formation operate simultaneously during high-temperature oxidation of iron, causing oscillating stress cycles, which are related to layer damage, and ultimately to unsatisfactory oxidation resistance;

- the residual stresses after cooling exist also in the form of gradients due to abrupt changes in thermal expansion occurring at the inner scale interfaces.

Acknowledgments The authors would like to thank BESSY and HASYLAB for the allocation of beamtime. Thanks are extended to I. Denks, J. Gibmeier, G. Wagener (HZB), Dr. A. Rothkirch and Dr. T. Wroblewski (HASYLAB) for experimental support during the diffraction experiments with synchrotron radiation. Dr. A. Kostka and Dr. C. Barbatti (MPIE) are acknowledged for their help during the SEM and EBSD sessions. This work was funded by the "Fonds zur Förderung der wissenschaftlichen Forschung" FWF, Vienna, Austria. Further support was provided by the European Community within the framework of the Research Infrastructure Action under the FP6 Program "Structuring the European Research Area"-Contract RII3-CT-2004-506008. 
Open Access This article is distributed under the terms of the Creative Commons Attribution Noncommercial License which permits any noncommercial use, distribution, and reproduction in any medium, provided the original author(s) and source are credited.

\section{References}

1. M. Schütze, in Protective Oxide Scales and Their Breakdown, ed. D. R. Holmes (The Institute of Corrosion and Wiley Series on Corrosion and Protection, John Wiley \& Sons Ltd, Chichester, UK, 1997), Chapter 4.

2. D. J. Baxter and K. Natesan, Reviews on High Temperature Materials 5, 149 (1983).

3. H. E. Evans, International Materials Reviews 40, 1 (1995).

4. N. B. Pilling and R. E. Bedworth, Journal of the Institute of Metals 29, 529 (1923).

5. F. N. Rhines and J. S. Wolf, Metallurgical Transactions 1, 1701 (1970).

6. A. Atkinson, Corrosion Science 22, 347 (1982).

7. D. R. Clarke, Acta Materialia 51, 1393 (2003).

8. B. Pieraggi and R. A. Rapp, Acta Metallurgica 36, 1281 (1988).

9. N. Vallino, L. Lahoche, J. M. Roelandt, V. Lorman, S. B. Rochal, L. Gaillet, and G. Moulin, Computational Materials Science 19, 329 (2000).

10. B. Panicaud, J. L. Grosseau-Poussard, and J. F. Dinhut, Applied Surface Science 252, 5700 (2006).

11. R. Krishnamurthy and D. J. Srolovitz, Acta Materialia 52, 3761 (2004).

12. A. G. Goursat and W. W. Smeltzer, in Oxidation of Iron, High-temperature Materials, Coatings and Surface Interactions, ed. J. B. Newkirk (Freund Publ. House, Tel Aviv, 1980).

13. H. S. Hsu, Oxidation of Metals 26, 315 (1986).

14. B. Panicaud, J. L. Grosseau-Poussard, P. Girault, J. F. Dinhut, and D. Thiaudière, Applied Surface Science 252, 8414 (2006).

15. B. Panicaud, J. L. Grosseau-Poussard, P. O. Renault, J. F. Dinhut, D. Thiaudière, and M. Gailhanou, Applied Surface Science 206, 149 (2003).

16. B. J. Kooi, M. A. J. Somers, R. H. Jutte, and E. J. Mittemeijer, Oxidation of Metals 48, 111 (1997).

17. S. Corkovic and A. R. Pyzalla, Materials and Corrosion 55, 341 (2004).

18. C. Juricic, H. Pinto, D. Cardinali, M. Klaus, Ch. Genzel, and A. R. Pyzalla, Oxidation of Metals $\left(450^{\circ} \mathrm{C}\right)$. doi:10.1007/s11085-009-9162-1.

19. Ch. Genzel, I. A. Denks, J. Gibmeier, M. Klaus, and G. Wagener, Nuclear Instruments and Methods A 578, 23 (2007).

20. I. A. Denks and Ch. Genzel, Nuclear Instruments and Methods B 262, 87 (2007).

21. W. Reimers, A. R. Pyzalla, A. Schreyer, and H. Clemens, Neutrons and Synchrotron Radiation in Engineering Materials Science, Chapter 10 (Wyley-VCH, Weinheim, Germany).

22. H. -R. Wenk, S. Matthies, J. Donovan, and D. Chateigner, Journal of Applied Crystallography 31, 262 (1998).

23. V. Hauk, Structural and Residual Stress Analysis by Nondestructive Methods, Chapter 2.072 (Elsevier, Amsterdam, 1997).

24. C.-H. Ma, J.-H. Huang, and H. Chen, Thin Solid Films 418, 73 (2002).

25. J.-H. Huang, C.-H. Ma, and H. Chen, Surface and Coatings Technology 200, 5937 (2006).

26. T. Dümmer, B. Eigenmann, and D. Löhe, Materials Science Forum 321-324, 81 (2000).

27. T. Dümmer, B. Eigenmann, and D. Löhe, Materials Science Forum 347, 423 (2000).

28. T. Dümmer, B. Eigenmann, M. Stüber, H. Leiste, D. Löhe, H. Müller, and O. Vöhringer, Zeitschrift fuer Metallkunde/Materials Research and Advanced Techniques 90, 780 (1999).

29. Ch. Genzel, Materials Science and Technology 21, 10 (2005).

30. M. Leoni, U. Welzel, P. Lamparter, E. J. Mittemeijer, and J.-D. Kamminga, Philosophical Magazine A 81, 597 (2001).

31. U. Welzel, M. Leoni, and E. J. Mittemeijer, Philosophical Magazine 83, 603 (2003).

32. R. W. Rice, Journal of Materials Science Letters 13, 1261 (1994).

33. A. Reuss, Zeitschrift für Angewandte Mathematik und Mechanik 9, 49 (1929).

34. M. Van Leeuwen, J.-D. Kamminga, and E. J. Mittemeijer, Journal of Applied Physics 86, 1904 (1999). 
35. Landolt-Börnstein, in Condensed matter-Ferroelectrics and Related Substances III/36, Oxides, eds. Y. Shiozaki, E. Nakamura, and T. Mitsui (Springer, 2001).

36. T. J. Ahrens, Mineral Physics and Crystallography-A Handbook of Physical Constants, Chapter 2-5 (American Geophysical Union, Washington, 1995).

37. I. C. Noyan and J. B. Cohen, Residual Stress Measurement by Diffraction and Interpretation (Springer, New York, 1987), p. 190.

38. I. C. Noyan, S. K. Kaldor, P. C. Wang, and J. L. Jordan-Sweet, Review of Scientific Instruments 70, 1300 (1999).

39. J. L. Jordan-Sweet, IBM Journal of Research and Development 44, 471 (2000).

40. I. Svedung, B. Hammar, and N.-G. Vannerberg, Oxidation of Metals 6, 21 (1973).

41. R. Y. Chen and W. Y. D. Yuen, Oxidation of Metals 59, 433 (2003).

42. N. Birks, G. H. Meier, and F. S. Pettit, Introduction to the High-temperature Oxidation of Metals (Cambridge University Press, Cambridge, 2006).

43. L. Tan, Y. Yang, and T. R. Allen, Corrosion Science 48, 4234 (2006).

44. L. Tan, Y. Yang, and T. R. Allen, Corrosion Science 48, 3123 (2006).

45. J. Stringer, Corrosion Science 10, 513 (1970).

46. S. Taniguchi and D. L. Carpenter, Corrosion Science 19, 15 (1979).

47. P. Kofstad, High Temperature Corrosion (Elsevier Applied Science Publishers Ltd, London, 1988), p. 233.

48. B.-K. Kim and J. A. Szpunar, Scripta Materialia 44, 2605 (2001).

49. R. L. Higginson, B. Roebuck, and E. J. Palmiere, Scripta Materialia 47, 337 (2002).

50. H. L. Bernstein, Metallurgical Transactions A 18A, 975 (1987).

51. K. Ueno, S.-I. Pyun, and M. Seo, Journal of the Electrochemical Society 147, 4519 (2000).

52. C. Xu and W. Gao, Materials Research Innovations 3, 231 (2000).

53. T. E. Mitchell, D. A. Voss, and E. P. Butler, Journal of Materials Science 17, 1825 (1982).

54. H.-J. Engell, Acta Metallurgica 6, 439 (1958).

55. C. Carel and J. R. Gavarri, Materials Research Bulletin 11, 745 (1976).

56. J. Berthon, A. Revcolevschi, H. Morikawa, and B. Touzelin, Journal of Crystal Growth 47, 736 (1979).

57. R. M. Hazen and R. Jeanloz, Reviews of Geophysics and Space Physics 22, 37 (1984).

58. E. R. Jette and F. Foote, The Journal of Chemical Physics 1, 29 (1933).

59. L. Himmel, R. F. Mehl, and C. E. Birchenall, Transactions AIME, Journal of Metals 197, 827 (1953).

60. H. J. Frost and M. F. Ashby, Deformation Mechanism Maps: The Plasticity and Creep of Metals and Ceramics, Chapter 14 (Elsevier, London, 1982).

61. H. Buscail, E. Sciora, J. P. Larpin, and N. Gerard, Oxidation of Metals 48, 417 (1997).

62. H. Buscail, M. F. Stroosnijder, Y. P. Jacob, and E. Sciora, Materials Science and Engineering A 262, 184 (1999).

63. A. G. Crouch and J. Robertson, Acta Metallurgica et Materialia 38, 2567 (1990).

64. P. Kofstad, Oxidation of Metals 24, 265 (1985).

65. M. I. Manning and E. Metcalfe, CEGB-Report RD/L/N15/75 (Central Electricity Generating Board, 1975).

66. Y. S. Touloukian, R. K. Kirby, R. E. Taylor, and P. D. Dessai, Thermophysical Properties of Matter, Thermal Expansion, Metallic Elements and Alloys, Vol. 12 (Plenum Publishing Corporation, New York, NY, 1975), p. 57.

67. Y. S. Touloukian, R. K. Kirby, R. E. Taylor, and T. Y. R. Lee, Thermophysical Properties of Matter, Thermal Expansion, Nonmetallic Solids, Vol. 13 (Plenum Publishing Corporation, New York, NY, 1977), p. 271.

68. Y. Hidaka, T. Anraku, and N. Otsuka, Oxidation of Metals 59, 97 (2003). 